\title{
Warmer and wetter or warmer and dryer? Observed versus simulated covariability of Holocene temperature and rainfall in Asia
}

\author{
Kira Rehfeld ${ }^{\mathrm{a}, *}$, Thomas Laepple ${ }^{\mathrm{a}}$ \\ ${ }^{a}$ Alfred Wegener Institut Helmholtz-Zentrum für Polar- und Meeresforschung, \\ Telegrafenberg A43, 14473 Potsdam, Germany.
}

\section{Abstract}

Temperatures in Asia, and globally, are very likely to increase with greenhouse gas emissions, but future projections of rainfall are far more uncertain. Here we investigate the linkage between temperature and precipitation in Asia on interannual to multicentennial timescales using instrumental data, late Holocene paleoclimate proxy data and climate model simulations. We find that in the instrumental and proxy data, the relationship between temperature and precipitation is timescale-dependent. While on annual to decadal timescales, negative correlations dominate and thus cool summers tend to be rainy summers, on longer timescales precipitation and temperature are positively correlated; cool centuries tend to be dryer centuries in monsoonal Asia. In contrast, the analyzed CMIP5/PMIP3 climate model simulations show a negative correlation between precipitation and temperature on all timescales. Although many uncertainties exist in the interpre-

\footnotetext{
${ }^{*}$ Corresponding Author.

Email addresses: krehfeld@awi.de (Kira Rehfeld), tlaepple@awi.de (Thomas Laepple)
} 
tation of the proxy data, there is consistency between them and the instrumental evidence. This, and the persistence of the result across independent proxy datasets, suggests that the climate model simulations might be considerably biased, overestimating the short-term negative associations between regional rainfall and temperature and lacking long-term positive relationships between them.

Keywords: Asian summer monsoon, temperature, precipitation, climate variability

\section{Introduction}

2

The Asian summer monsoon winds transfer moisture from the tropical oceans onshore and release it as they cool while traveling inland, driven mainly by the thermal gradient between the surrounding oceans and the land surface (Fig. 1 and Turner and Annamalai [44]). The state and fate of the monsoon is of particular importance to the agricultural economies across Asia, yet, globally and across Asia, precipitation projections are far more uncertain than those for temperature [15].

Simulations of future precipitation in the Coupled Model Intercomparison Project Phase 3 [CMIP3, 27] showed no consistent response in Asia to increasing temperatures. The models in the more recent CMIP5 ensemble [40] largely agree on an increase in rainfall amount and variability [28, 36]. Nevertheless, the skill of the models in representing key features of the Asian summer monsoon, such as its onset timing, duration and intensity has not improved significantly from CMIP3 to CMIP5 [28, 36]. Improved consistency across models therefore does not guarantee improved future prediction 


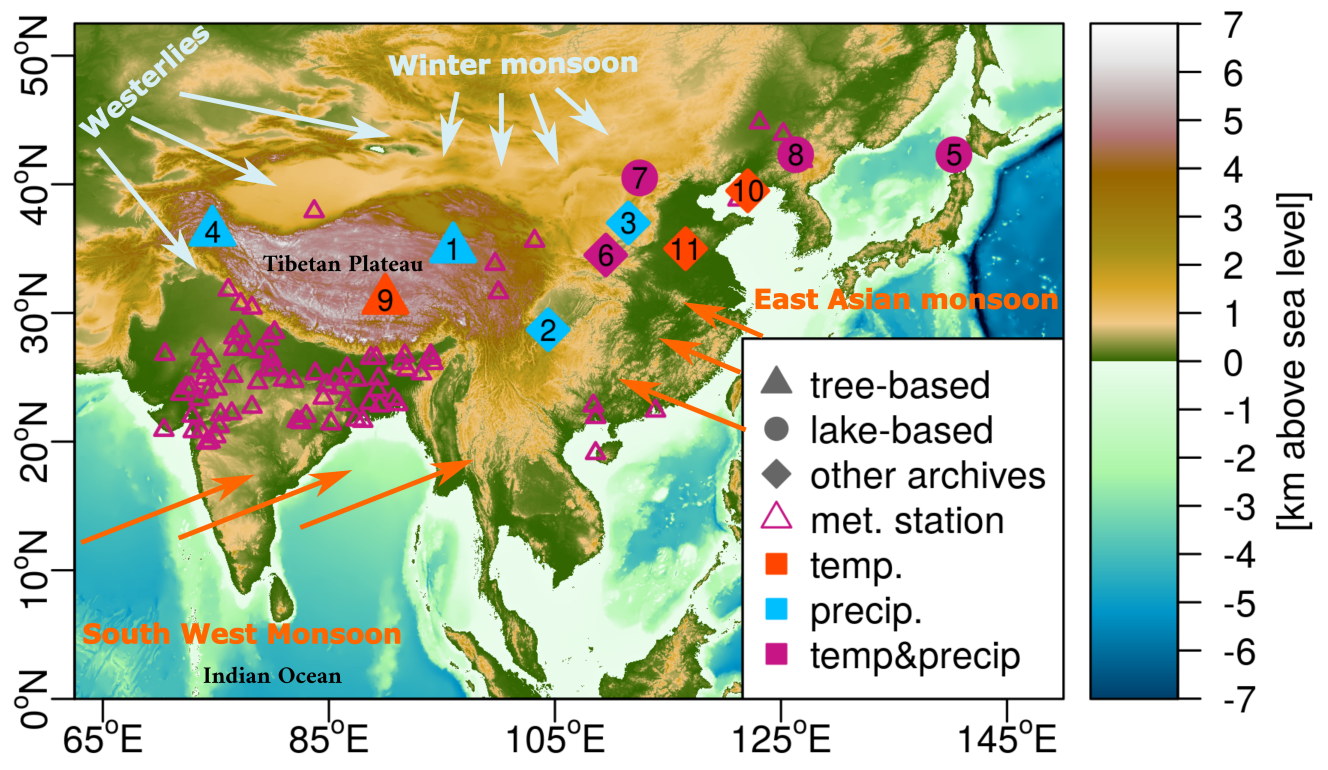

Figure 1: Overview of the study area and the dominant summer (orange) and winter (light blue and yellow) wind systems. Symbols show the paleoclimate proxy data sites and meteorological stations for which Table 1 and Supplementary Table 2 give more details. 
skill, as many models have difficulties in simulating monsoon rainfall and variability $[22,44]$.

In theory, global rainfall is likely to increase in a warmer world, as the partial pressure of water vapor at saturation increases by $\sim 7 \%$ per $1^{\circ} \mathrm{C}$ temperature increase, following the Clausius-Clapeyron relationship [15]. Locally, precipitation responses are difficult to project, as it is unclear if the atmospheric pathways which relay evaporated oceanic moisture onto the continents remain the same in a warmer atmosphere with greenhouse gas, aerosol load, regional vegetation and land use changes. Analyzing trends of the last 50 years showed a warming but no consistent precipitation change across Asia [44]. The thermal response to greenhouse gas forcing is better known than the hydrological response. Thus, complementary information on future rainfall can be gained by analyzing the relationship of precipitation and temperature (T-P relationship) on observational datasets. Direct extrapolation of results based on largely naturally forced past temperature variability onto a future where temperature changes are dominated by anthropogenic forcing, however, needs to be treated with caution, as the monsoon circulation response may also be specific to the forcing, rather than temperature changes.

On daily to interannual timescales, negative correlations between local temperatures and precipitation in Asia were estimated from satellite and station data as well as from model simulations $[1,3,42,46]$. This evident negative correlation between local temperature and precipitation roots in fundamental aspects of the hydrological cycle: rainy days tend to have a higher cloud cover and soil moisture, and thus lower temperatures through 
insolation shielding and evaporative cooling, hot days are more likely to be dry [3, 46, and references therein]. Over land, this anticorrelation was found to be strongest in the summer months but persisted throughout the year. On daily timescales, Williams et al. [46] observed differences to the monthly analysis of Trenberth [42] and concluded that a timescale dependency of processes influencing the T-P relationship is already relevant between daily and monthly scales. Due to the shortness of the observational record, however, station- or satellite-based correlation studies are mostly limited to shorter than decadal timescales.

Within monsoonal Asia, slow processes acting on interannual to centennial scales are likely to modify the boundary conditions for the monsoon circulation, modulating its intensity, duration and distribution. Most of them result in a positive association between regional temperatures, and rainfall amounts: On the oceanic side, interannual to centennial precipitation changes in monsoonal Asia have been attributed to warmer surface temperatures in the subtropical Pacific and the Indian Ocean, the source areas of monsoonal moisture [42]. In the atmosphere, reducing (increasing) the albedo of the Tibetan Plateau by lower (higher) snow cover in a warming scenario, was proposed to increase (decrease) monsoonal intensity by damping (strengthening) its role as an amplifying elevated heat source [50]. On centennial timescales, proxy data suggests a wetter summer monsoon during the warm Medieval Climate Anomaly, and a weakening during the cold period thereafter [e.g. 7, 33, 49]. This is consistent with the notion that the Intertropical Convergence zone extends further north in warm periods than in cold periods [34]. 


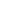

On timescales of decades to centuries the nature and timescale-dependency of the T-P relationship within Asia and beyond is far from being understood. Here, we provide a systematic investigation of the T-P interdependence from decadal to multi-centennial timescale. Therefore, we employ paleoclimate proxy data, instrumental datasets and model simulations to obtain a comprehensive view of the relationship between temperature and precipitation changes across Asia.

\section{Data}

\subsection{Paleoclimate Data}

We identified eleven suitable Holocene paleoclimate proxy reconstructions for temperature and/or precipitation in the region $60-150^{\circ} \mathrm{E}$ and $5-50^{\circ} \mathrm{N}$ after a quality screening of available data. The datasets cover multiple proxies, reconstruction techniques and resolutions in the area depicted in Fig. 1.

We only included proxy records which were interpreted as temperature and/or precipitation sensitive by the original authors. Locations, archive and proxy type, seasonal coverage and reconstruction methods of the datasets are given in Table 1. In addition, Table 1 also gives the temporal resolution and the temporal span over which the records were evaluated. The datasets had to cover more than 400 years of the Holocene, between 10 000BP and present day, and had to have sufficient overlap with at least one other complementary record. Note that we did not consider individual speleothem $\delta^{18} O$ time series for our analyses, as the attribution to precipitation or temperature may be ambiguous on long timescales [5]. Preliminary analyses indicated 
that individual cave speleothem time series correlated more strongly with the temperature reconstructions in the set of reconstructions, than with the rainfall reconstructions (not shown). Some speleothem oxygen isotope time series were included in the precipitation reconstruction of Tan et al. [38].

Reconstruction methods may strongly influence the character and trends of quantitative paleoclimate recostructions, especially when multiple climate variables are derived based on the same proxy data [17, 41]. One temperature dataset had to be excluded, because it was by construction negatively correlated to the simultaneous precipitation reconstruction [Number 3 in Table 1, 48]. These climate variables were based on tree-ring and historical drought/flood observation data, and then processed by principle component analyses. Significant axes were combined positively for precipitation, and negatively for temperature. As the temperature reconstruction showed considerably lower skill than that for precipitation [48] we only retained the summer precipitation time series in the database.

Two proxy datasets were considered regionally consistent and comparable, if they both stem from the South-West-Summer-Monsoon (SWSM) domain, west of $100^{\circ}$ E, or the East Asian Summer Monsoon (EASM) domain (Fig. 1). A comparison between SWM domain records and EASM records would not be appropriate, as the monsoon systems may act independently and asynchronously. An independent verification of all proxy reconstructions with meteorological observations is, unfortunately, not possible, as many reconstructions do not cover the instrumental era at a sufficient resolution - or at all. 
116

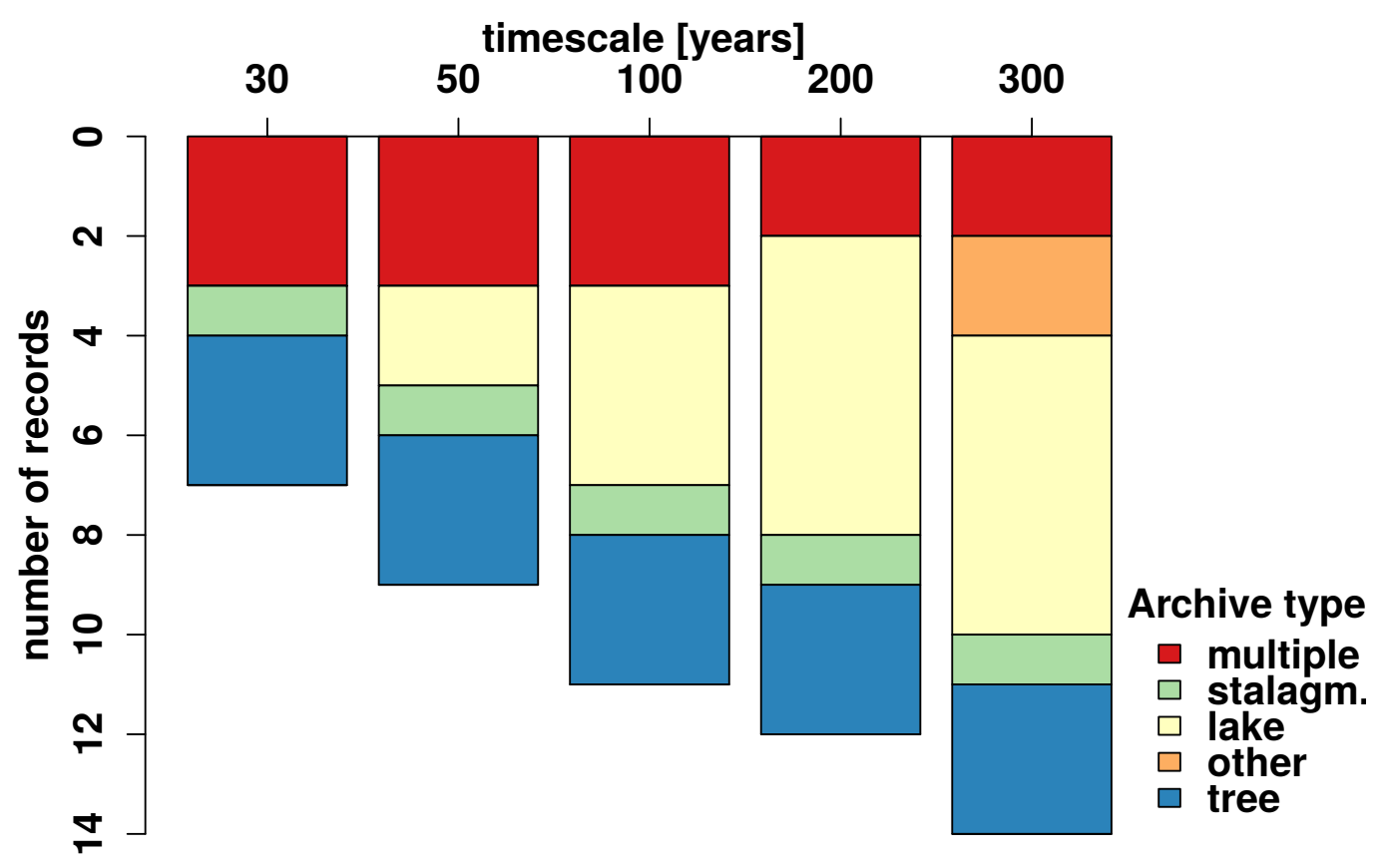

Figure 2: Paleoclimate proxy archive composition for each timescale.

\subsection{Model data}

We analyze the climate model simulations from the Coupled Model Intercomparison Project phase 5 (CMIP5) of the last millenium (past1000, 850-1850AD) forced with reconstructed solar, volcanic, GHG and aerosol forcing, and partly land use changes [40]. These nine millenium simulations, for which complete surface temperature and precipitation output was available, allow us to investigate the modeled relationship $r_{(t, p)}$ in response to largely natural forcing from annual to multidecadal timescales. If multiple ensemble members were available, only the first ensemble member was analyzed. To extend our analysis to centennial timescales we employ an orbital 
Table 1: Details for paleoclimate reconstructions used in this study. Locations marked with asterisks $(*)$ are based on data from multiple locations, and coordinates in the midst of the representative region are assumed. Sources are given in Supplementary Table 1.

\begin{tabular}{|c|c|c|c|c|c|c|c|c|}
\hline No. & Name & $\begin{array}{l}\text { Lat./Lon } \\
{\left[{ }^{\circ} \mathrm{N} / \mathrm{E}\right]}\end{array}$ & Archive & $\begin{array}{l}\text { Proxy/ Pa- } \\
\text { rameter }\end{array}$ & $\begin{array}{l}\text { Reconstruction } \\
\text { method }\end{array}$ & $\begin{array}{l}\text { Months } \\
\text { (temp./p }\end{array}$ & $\begin{array}{l}\text { Resolution (Span) [ka BP] } \\
\text { ecip.) }\end{array}$ & Reference \\
\hline 1 & Sheppard-P & $35 / 96$ & tree & $\begin{array}{l}\text { ring width } \\
\text { chronol- } \\
\text { ogy/ precip }\end{array}$ & $\begin{array}{ll}\text { Temporal } & \text { re- } \\
\text { gression } & \text { on } \\
\text { met.data } & \end{array}$ & $1-12$ & $.001(-.04-2.5)$ & [35] \\
\hline 2 & $\operatorname{Tan} 2011 \mathrm{Pr}$ & $29 / 104$ & multiple & $\begin{array}{l}\text { stalagmite } \\
\delta^{18} \mathrm{O} \quad \& \\
\text { docu- } \\
\text { ments/ } \\
\text { precip }\end{array}$ & $\begin{array}{l}\text { Comparison to } \\
\text { model simula- } \\
\text { tion, no cali- } \\
\text { bration }\end{array}$ & $1-12$ & $.01(-.05-1.9)$ & [38] \\
\hline 3 & NCPrecipIndex & $37 / 112^{*}$ & multiple & $\begin{array}{l}\text { tree \& doc- } \\
\text { uments/ } \\
\text { precip }\end{array}$ & $\begin{array}{l}\text { Temporal cal- } \\
\text { ibration of } \\
\text { PCA compo- } \\
\text { nents against } \\
\text { met.data }\end{array}$ & $1-12$ & $.001(-.05-.5)$ & {$[48]$} \\
\hline 4 & Karakoram & $36 / 75$ & tree & $\delta^{18} \mathrm{O} /$ rainfall & $\begin{array}{ll}\text { Temporal re- } & \\
\text { gression } & \text { on } \\
\text { met.data } & \end{array}$ & $10-2$ & $.001(-.05-1.0)$ & {$[43]$} \\
\hline 5 & Yakumo & $42 / 140$ & lake & $\begin{array}{l}\text { pollen/ } \\
\text { pre- } \\
\text { cip\&temp }\end{array}$ & $\begin{array}{l}\text { Spatial transfer } \\
\text { function (Mod- } \\
\text { ern Analogs) }\end{array}$ & $6,7,8 / 8$ & $.15(.04-5.5)$ & [20] \\
\hline 6 & Loess & $34 / 110$ & loess & $\begin{array}{l}\text { phytolyths/ } \\
\text { pre- } \\
\text { cip\&temp }\end{array}$ & $\begin{array}{l}\text { Spatial trans- } \\
\text { fer function } \\
\text { (Weighted Av- } \\
\text { eraging Partial } \\
\text { Least Squares) }\end{array}$ & $1-12$ & $.25(2.8-10)$ & [26] \\
\hline 7 & Daihai & $41 / 113$ & lake & $\begin{array}{l}\text { pollen/ } \\
\text { pre- } \\
\text { cip\&temp }\end{array}$ & $\begin{array}{l}\text { Spatial trans- } \\
\text { fer function } \\
\text { (Weighted Av- } \\
\text { eraging Partial } \\
\text { Least Squares) }\end{array}$ & $1-12 / 8$ & $.38(.01-10)$ & {$[47]$} \\
\hline 8 & Sihailongwan & $42 / 126$ & lake & $\begin{array}{l}\text { pollen/ } \\
\text { pre- } \\
\text { cip\&temp }\end{array}$ & $\begin{array}{l}\text { Spatial trans- } \\
\text { fer function } \\
\text { (Weighted Av- } \\
\text { eraging Partial } \\
\text { Least Squares) }\end{array}$ & $1-12 / 8$ & $.06(.15-10)$ & {$[37]$} \\
\hline 9 & PagesAsia2kT & $31 / 90^{*}$ & tree & multiple & $\begin{array}{l}\text { Ensemble } \\
\text { point-by-point } \\
\text { regression onto } \\
\text { gridded station } \\
\text { data }\end{array}$ & $1-12$ & $.001(-.04-1.2)$ & [30] \\
\hline 10 & Shihua2003 & $39 / 116$ & stal & $\begin{array}{l}\text { layer } \\
\text { thickn./temp }\end{array}$ & $\begin{array}{ll}\text { Temporal re- } \\
\text { gression } & \text { on } \\
\text { met.data } & \end{array}$ & $5-8$ & $.001(-.04-2.6)$ & [39] \\
\hline 11 & ChinaTempGe & $35 / 110$ & multiple & multiple/tem & $\begin{array}{ll}\text { Temporal re- } \\
\text { gression }\end{array}$ & $1-12$ & $.01(-.025-1.8)$ & [11] \\
\hline
\end{tabular}


only forced 6000-year ECHAM5-MPIOM simulation [by 9, denoted "orbital" in the following]. To cover shorter timescales, and thus to provide a link to the instrumental record, we employ the 47 historical (hist, 1850-2000 AD) CMIP5 simulations including natural as well as anthropogenic forcing [40]. A list of the model simulations is provided in Supplementary Table 1.

\subsection{Instrumental data}

Monthly observations from 78 stations were obtained from the Global Historical Climate Network v2 database [GHCN, 31] and averaged to obtain seasonal values at annual resolution. A year's seasonal average was retained, if joint temperature and precipitation observations were available for all months of the season at the station, and a station time series was considered if at least 50 years of such joint observations could be obtained. Station locations are indicated in Fig. 1, and the number of years each station covers for summer/annual averages is given in Supplementary Table 2. To compare observations to the CMIP5 models, we resampled the 47 CMIP5 historical model simulations by bilinear interpolation at station/proxy locations and censored the model data to contain the same years as the instrumental records. As a sensitivity test, we additionally analyzed gridded instrumental datasets from the Climate Research Unit (CRU) for precipitation [Hulme Global Land Precipitation Data, ref. 13] and temperature [CRUTEM v.4.2, ref. 16]. The gridded datasets were analyzed in the same way, and for the same time periods, as the model data. We focus our discussion on the GHCN instrumental station data, as any processing steps required for deriving the gridded dataset such as infilling of missing data and interpolation influences 
the precipitation to temperature relationship in unknown ways that are difficult to quantify.

\section{Methods}

\subsection{Paleoclimate data analysis}

To investigate the timescale-dependency of the T-P relationship we lowpass filter the data using different cutoff frequencies prior to the correlation estimation. Orbital-to-millennial scale variability in the Holocene paleoclimate data was removed by subtraction of a millennial-scale nonlinear trend from a Gaussian kernel smoother with an effective cutoff frequency (halved magnitude of frequency response) $f_{\text {low }}=1 / 1000$ years. A second Gaussian smoother was passed over the timeseries, with a width given by $f_{h i}=(1 / 30,1 / 50,1 / 100 \ldots)$ years. This results in a bandpassed time series from which a timescale-dependent Pearson correlation can be estimated robustly against irregular sampling of the time series [32]. Significance testing is based on 2000 Monte Carlo simulations using AR1 surrogates with the lag-1 autocorrelation estimated from the $f_{\text {low }}$-detrended proxy time series, and with the original temporal sampling [32].

In a first screening step the original time series had to overlap with more than 50 samples. Then, a pair of records was incorporated for a given timescale of $\alpha$ years if their overlap $L$ was more than $3 \alpha$, and the mean inter-sample distance was smaller than than $0.5 \alpha$ (Figure 2 and Supplementary Fig. 4). Consider for example two records overlapping over 500 years, at a sample spacing of 10 years for both time series. At a timescale of $\alpha=100$ years, a cross-correlation would be computed, since the overlap is $5 \alpha=500$ years 
and the average sample spacing is smaller than $0.5 \alpha=50$ years.

\subsection{Instrumental data analysis}

Both instrumental and model timeseries were linearly detrended and analyzed using timescale dependent Gaussian kernel correlation [32] as for the proxy data. The correlation map fields shown in Fig. 3b were regridded to T63 resolution using bilinear interpolation to allow a comparison of the correlation fields.

\section{Results}

4.1. Multidecadal to centennial-scale temperature to precipitation relationship

On multi-decadal timescales, the CMIP5 past1000 simulations show a negative summer (JJA) temperature-precipitation correlation (Fig. 3b) over most of Asia's landmass. In particular above peninsular India and Central China, the majority of the individual models agree on a negative correlation sign. The most negative multi-model mean correlations are found above Central India $(-0.5)$ and in Central China $(-0.3)$, the most positive associations above the Pacific, off the coast of Japan (0.6), and in the South China Sea (0.3). The predominant negative relationship over most of the land persists across all testable timescales in summer, winter as well as on the annual mean (Supplementary Figs. 1-3). Above the Tibetan Plateau and the surrounding ocean basins, the correlation is largely positive, but the model T-P relationship is not as consistent in between the models as above the mainland, indicated by fewer plus-signs on Fig. 3b. This may be related to the 
fact that the representation of the orography of the Himalayan range changes with model resolutions and influences the simulated precipitation [6]. The estimates for the orbital simulation agree well with the multi-model-mean of the past1000 simulation at 30 and 50 year timescale and show that the negative model correlation also persists on decadal to centennial timescales, as shown in Fig. 4.

In contrast, analyzing the proxy data reveals a striking discrepancy between the simulated and reconstructed temperature precipitation relationship: Proxy-based T-P correlations are overall positive, and become stronger at decadal to centennial timescales (Fig. 3). On average, the proxies suggest a positive relationship with $r_{(t, p)} \approx+0.3$ at a 30-year timescale, while the multi-model mean summer (JJAS) relationship at the proxy locations shows an T-P anticorrelation of -0.3 . Most $(70 \%)$ of the individual proxy based correlations are significant at the 90 or 99\%-level on centennial timescale, accounting for autocorrelation as described in Sect. 3.1. The proxy-based T-P correlations are outside the intermodel spread (compare, e.g., Supplementary Figs. 1 and 2. for the individual model results on all timescales). Thus, the proxy data suggest that warm centuries tended to be wetter centuries, whereas the simulations suggest that warm centuries corresponded to drier centuries.

\subsection{Annual to decadal scale temperature to precipitation relationship}

To test whether a similar difference between models and observations is detectable in the instrumental period, we compare the T-P correlation from GHCN instrumental data and the 47 CMIP5 historical simulations.

The observed decadal-scale mean correlation, averaged across all stations, be- 
(a) Reconstruction-based correlations

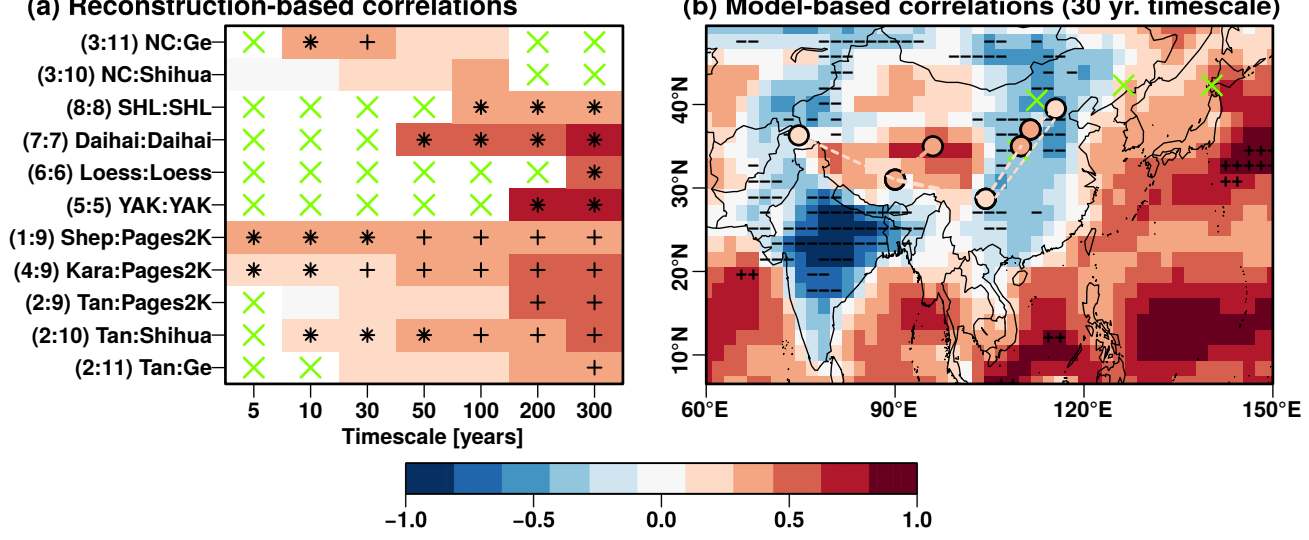

Figure 3: Reconstructed and model-based correlation between temperature and precipitation. (a) Timescale dependence of proxy-based correlations. Asterisks indicate significance at the 99\%-level, plus-signs at the 90\%-level. Green crosses indicate insufficient data. Numbers refer to entries in Table 1, where proxy details are provided. (b) CMIP5 past1000 multimodel mean correlation map between summer (JJAS) temperature and precipitation for the 30-year timescale. Minus (plus) signs indicate, that at least 8 out of the 9 models agree on a negative (positive) sign of the correlation. The color of the circles gives local proxy correlations on the same timescale, dashed lines the correlation between nearby sites. 


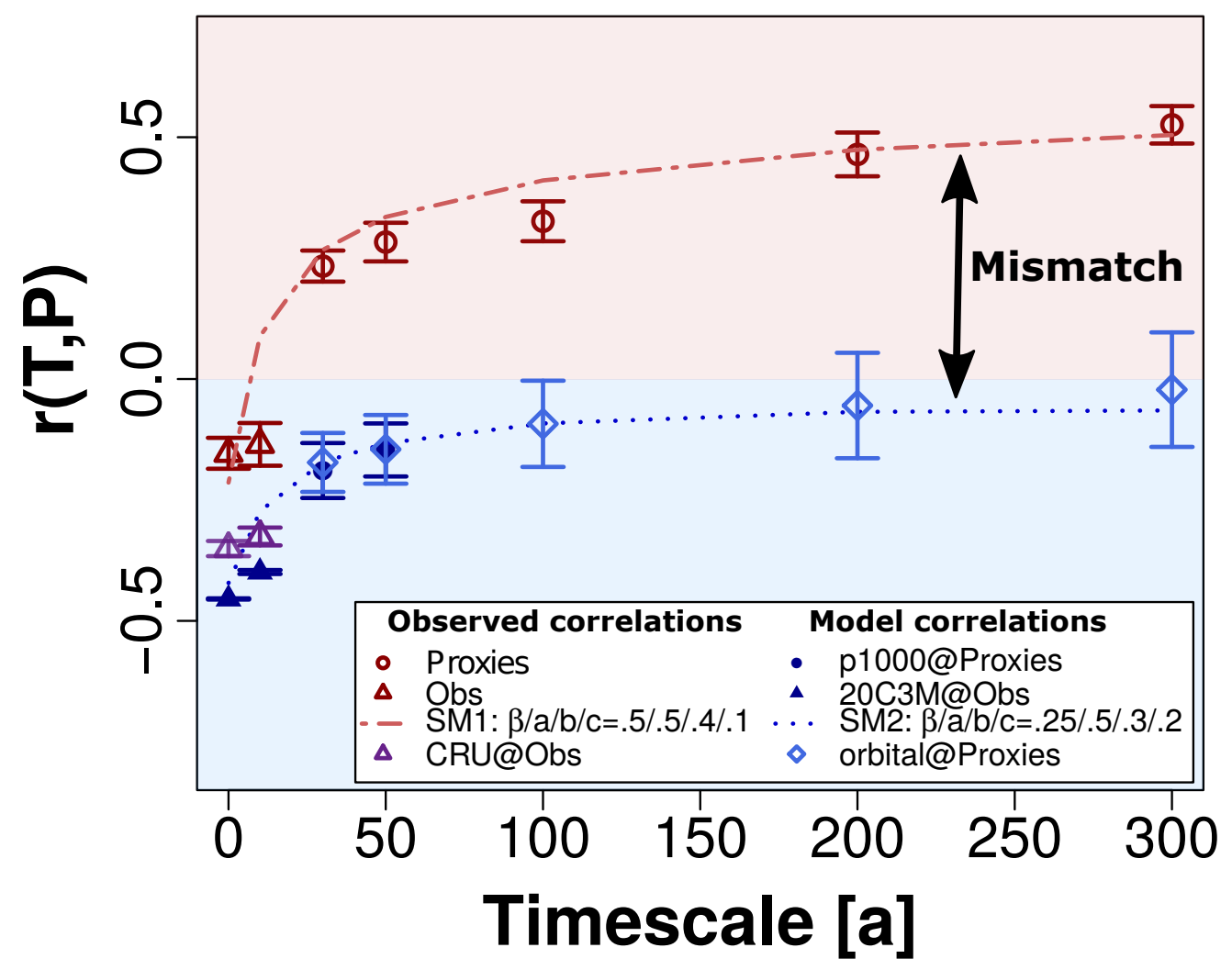

Figure 4: Timescale-dependent correlation in observations, models and proxy data averaged across station and proxy locations. Symbols and error bars denote the mean correlation between surface temperature and precipitation for the observations and the models and its standard error. The stochastic model (broken lines) fits both proxy and GCM data, with lower temporal persistence $(\beta)$ and weaker positive coupling at long timescales (b) for the GCMs. 
tween summer temperature and rainfall amount is weakly negative $\left(r_{(t, p)}=\right.$ $-0.13)$. For the same locations and years, the simulated decadal-scale multimodel mean correlation at the stations shows a clear negative correlation $\left(r_{(t, p)}=-0.4\right)$.

The simulated correlation patterns show some model dependence (Fig.3). Subsequently, the model-observation difference in correlation is also modeldependent, but most models (37 of 46) reveal a stronger negative average correlation than the observations (Fig. 5). Interestingly, the offset between observed and simulated $r_{(t, p)}$ on decadal timescales is similar to the discrepancy observed between proxy reconstruction-based and past1000 $r_{(t, p)}$ on multi-decadal timescales (Fig.4). The direction and magnitude of the model-observation mismatch is therefore consistent across instrumental and proxy data and persists on all analyzed timescales. It is interesting to note that analyzing the CRU gridded datasets instead of the raw station data results in a much smaller difference between the observed (gridded) and model based T-P correlations (Fig. 4). Analyzing the gridded data at the station locations, we obtain a decadal-scale T-P correlation of $\left(r_{(t, p)}=-0.32\right)$.

\section{Discussion}

We observe a clear mismatch between the proxy reconstruction and instrumental based estimates of the T-P relationship and the estimates based on the coupled climate models. This discrepancy may be attributable to weaknesses in proxy reconstructions and instrumental data, deficiencies on the model side, or a combination of both. In the following sections we will explore several potential explanations. 


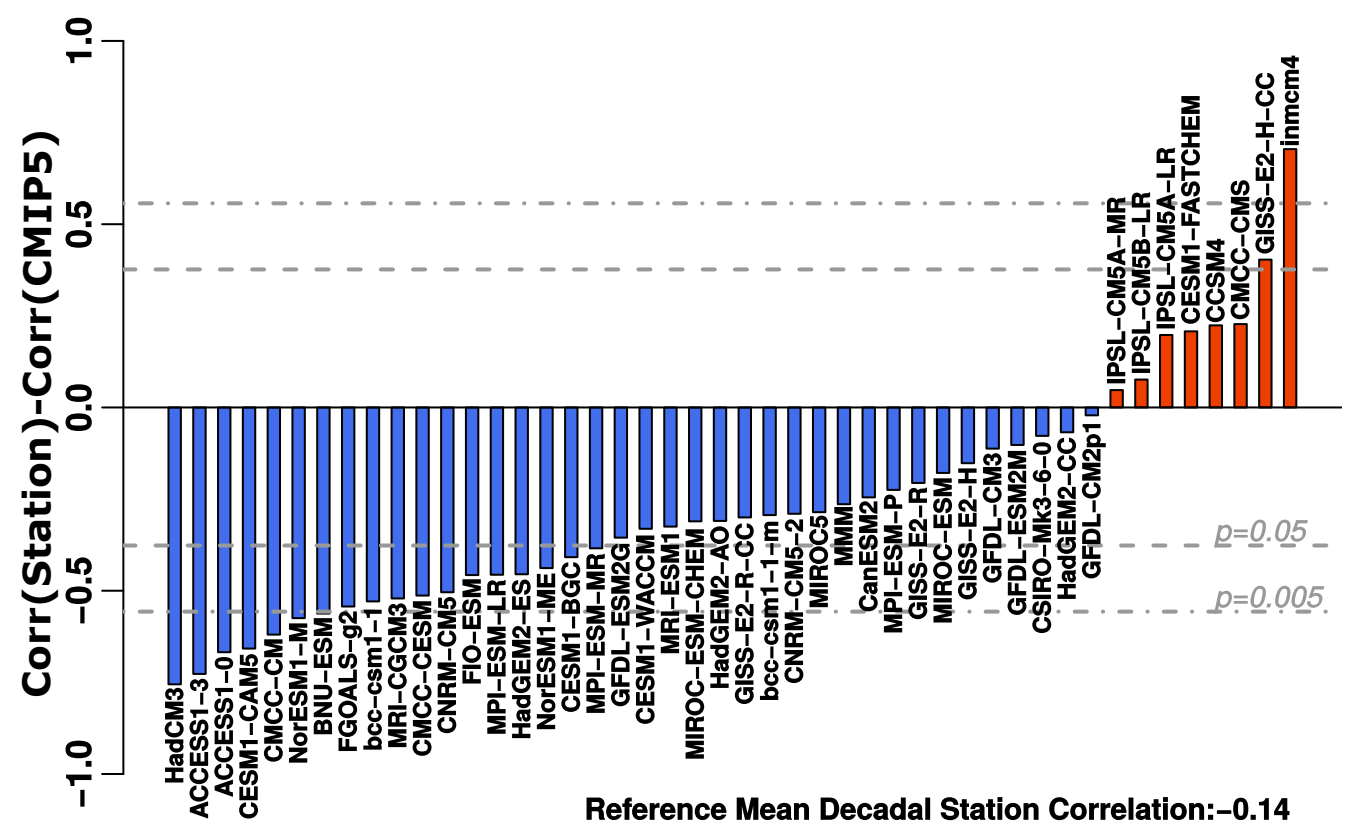

Figure 5: Offset between the CMIP5 historical temperature/precipitation correlations and the station-based correlations on decadal timescales. Critical values of the difference were computed based on the t-statistic with 20 degrees of freedom. Most models display stronger negative correlations than those calculated from the instrumental data. 


\subsection{Potential reasons for the mismatch on the observational side}

There are several levels, at which systematic proxy-dependent effects on the observed T-P relationship could occur.

Firstly, there is a possibility that positive correlations were induced by construction during the reconstruction of climate variables, particularly in studies where multiple variables are reconstructed based on the same multivariate dataset. This challenge is particularly important for multivariate terrestrial climate archives [17, 41], but also exists for tree-ring-based reconstructions [10]. We have excluded one dataset where the correlation was set by construction, as discussed in Section 2.1. If stalagmite $\delta^{18} \mathrm{O}$ time series [e.g. 49] were included as rainfall proxies, the overall correlation would become even more positive (results not shown). We find significant positive correlations $(\mathrm{p}<0.01)$ where temperature and precipitation variables were reconstructed from the same dataset and the same methods (Fig. 3). We do, however, also find significant positive correlations $(\mathrm{p}<0.05)$ between rainfall and temperature reconstructions when the proxy, its archive source, and the reconstruction methods differ.

Secondly, most proxy reconstructions are subject to considerable uncertainty concerning their recording season [24] and their recorded climate variable [17, 41]. Uncertainties with regard to the recording season in proxy reconstructions [24] are not a viable explanation for the model-data discrepancies, as the model correlation fields remain largely unchanged if annual or boreal winter season mean temperatures and precipitation are considered (Supplementary Figs. 1-3), and the T-P correlations in the GHCN station data are also not sensitive on the analyzed season $\left(\Delta r_{\mathrm{t}, \mathrm{p}}=r_{(t, p)}^{\mathrm{JJAS}}-r_{(t, p)}^{\mathrm{ann}}\right.$ is 
$0.03 \pm 0.04)$. Also, precipitation reconstructions which are directly based on biological archives (i.e. living organisms) may be drought-sensitive, and could reflect variations in soil moisture rather than precipitation. If local temperature and soil moisture in the models were positively correlated, this could close the gap between observations and models. This is, however, not the case as the correlation between temperature and soil moisture is even more negative than the one between temperature and precipitation (Fig. 6).

Thirdly, independent observational noise on the precipitation and temperature datasets would bias any correlation towards zero and thus lead to underestimation of the reconstructed correlation strength. For the instrumental data this effect should be strongest on interannual timescales as here the relative noise contribution is expected to be highest [18]. This might explain why the GHCN station data shows a weaker negative correlation than the gridded CRU data. As a gridcell often averages across multiple stations, this might reduce the observational noise compared to the GHCN station data. On the other hand, such an effect should be reduced on the decadal timescales but we observe a similar model-GHCN observation-gridded CRU observation offset on interannual and decadal timescales. Accounting for noise in the proxy data would even increase the model-data mismatch, as the true underlying positive T-P correlation would then expected to be higher.

Another potential reason for the mismatch could be that model data are given as regional (grid-box) averages, while station/proxy data reflect the local climate. Indeed, we find that the correlation in the gridded CRU dataset falls closer to the model data than the GHCN station dataset- shown in Fig. 4. Given that proxy records are often interpreted as reflecting the local 
climate conditions, we find that it is most appropriate to compare them to station data, instead of grid-box averages. However, we note that the spatial footprint of the specific proxy types, and the dependency of climate variability on the spatial scale, are important open questions for model-data comparisons, which will require further investigation.

Finally, paleoclimate proxy data often contain temporal uncertainty. Age uncertainty in one or both of the proxy reconstructions will bias the correlation towards zero [32], contrary to what would be needed to reconcile proxies and observations.

We note that the timescale-dependent change in $r_{(t, p)}$ (Fig.4) might be affected by the switch of the data type from instrumental data, used up to decadal timescales, to proxy data for longer timescales and the associated changes in the spatial coverage. As we sample the model at the observational sites, the change in spatial coverage does not influence the model-data comparison. To quantify a potential jump in the correlations due to a change in observation locations we employ gridded datasets to compare the correlation difference between proxy and station locations. The T-P mean correlation difference between proxy locations and station locations is small (-0.08 for the CRU gridded dataset, 0.01 for the historical multi-model mean). We therefore conclude that, although there may be a small change due to the location changes, there is no strong influence on the timescale-dependent relationship in Fig. 4.

None of described potential shortcomings on the proxy or instrumental data side can readily explain the offset between climate model and paleoclimate reconstruction-based correlation. While given the large number of 


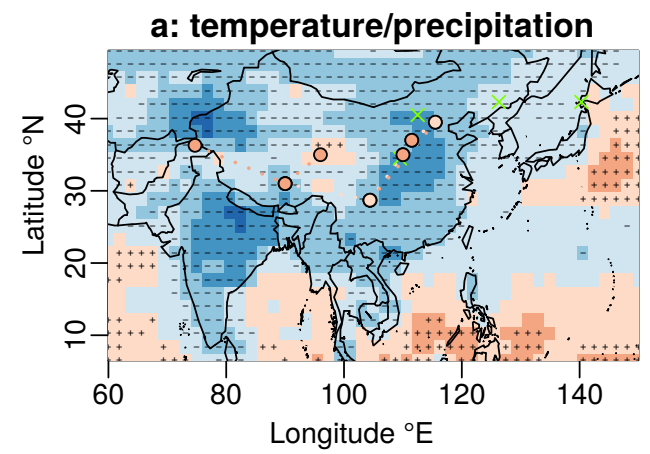

b: temperature/soil moisture

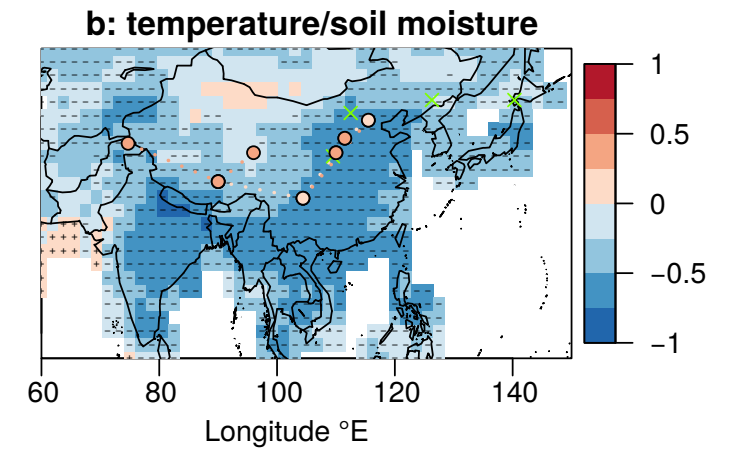

Figure 6: Correlation map for the 30-year timescale between summer (JJAS) temperature and precipitation (a) and temperature and soil moisture (b) for the two models (bcccsm-1 and MPI-ESM-P) for which all variables were available at the time of analysis. Minus (plus) signs indicate, that both models agree on a negative (positive) sign of the correlation. Proxy correlations between reconstructed temperature/precipitation are given in both panels as a reference.

possible influences upon the proxy reconstruction, we cannot rule out possible biases in the reconstructed relationship, the consistency between instrumental and different proxy evidence suggests that deficiencies in the climate models or in the experiment designs (missing or inadequately represented forcings) are at least partly responsible for the mismatch.

\subsection{Potential reasons for the mismatch on climate model side}

Mechanisms and processes relating temperature and precipitation variability to each other involve atmospheric dynamics as well as land and ocean surface processes. The offset we observe may be caused by a weakness of positive feedback to balance negative correlations between temperature and precipitation on short timescales, or an overestimation of the negative feedback strength on short timescales. 
Stronger negative terrestrial surface T-P correlations in climate models than in the observations have been previously noted on daily [46], monthly [42] and interannual timescales [3]. Several model-based studies have shown that dry (wet) soil tends to suppress (favor) precipitation generation through evapotranspiration decreases (increases), which change local convection, circulation and moisture advection [see, e.g. 29, 45, 46, and references therein]. Regions such as peninsular India and South-Central China which show dry and warm biases in CMIP5 models [as observed by e.g. 4, 22, 29] may therefore be directly linked to regions with particularly negative T-P relationships, through a negative impact of dryness on moisture advection. Precipitation underestimation and temperature overestimation on daily to interannual timescales could therefore be a likely candidate for explaining the negative $r_{(t, p)}$ offset.

Positive moisture-advection feedbacks relate the monsoon precipitation to a strengthening of the landward circulation, which in turn supplies more moisture. They may dominate the seasonal heat balance on long timescales, and explain abrupt changes in monsoon rainfall under small changes in external forcing [21]. In the conceptual model of Levermann et al. [21], higher summer temperatures increase the seasonal land-sea thermal contrast due to the different heat capacity of land and ocean, strengthening the monsoon onset circulation and allowing for more precipitation. Weaknesses in the simulation of these seasonal processes may explain the lack of positive feedbacks between temperature and rainfall changes on long timescales.

There is also considerable influence of teleconnections and external forcing on rainfall across Asia, which may modify the T-P relationship on long 
timescales. Changes in the frequency of El-Niño/Southern Oscillation events or the states of the Indian Ocean Dipole or the Pacific Decadal Oscillation may lead to different temperature and precipitation changes than atmospheric aerosols, solar insolation or greenhouse gas changes [23]. As we analyze fully forced model simulations to derive the correlation structure up to multidecadal timescales and compare the same years of observations and model data in the instrumental period where strong changes in the external forcing occur, different modulations from internal and external forcing should not affect our comparison. The change of determining $r_{(t, p)}$ in the fully forced past1000 simulations (for timescales faster than centennial) vs. in a single orbital-only simulation (for longer timescales) might influence the timescale dependency of the correlation, and leads to a higher uncertainty for the correlation estimate on the long timescales. However, the similar mean of $r_{(t, p)}$ in the orbital only simulation and the fully forced past1000 simulations further suggests a minor effect of the natural external forcing. This is consistent with the small influence of external forcing on regional climate variability found in [19].

Furthermore, CMIP5/PMIP3 models have been shown to underestimate temperature variability on multidecadal to millennial scales at the sea surface $[18,19]$, and in the atmosphere [25]. Most immediate and short-term mechanisms influencing the T-P relationship (cloud cover, soil moisture, evaporation) are expected to induce negative associations. On long timescales, slow-acting components of the earth system (e.g. glaciation changes, basinwide sea surface temperature modes, Intertropical Convergenze Zone shifts) might result in positive links, and could increase the memory of the system 
[25]. However, inadequate representation of such slow feedbacks may not be detectable by benchmarking against short observational data.

\subsection{Comparison using a stochastic model}

According to our analysis of proxy and instrumental data, the covariability of temperature and precipitation is timescale-dependent with a negative correlation on annual timescales. On long timescales from multidecadal to centennial, proxy evidence suggests that the relationship is positive. To describe the timescale-dependent behavior and get insights on potential mechanisms, we therefore derive a simple stochastic process-based model with parameters derived from the observed and simulated relationships.

\subsubsection{Definition}

We derive a set of coupled stochastic processes according to a timescaledependent coupling scheme, as illustrated in Fig. 7. 1000-year-long weatherand climate-like noise processes $W$ and $C$ are simulated using pink noise processes with a power-spectral density inversely proportional to the frequency, thus following a $1 / f^{\beta}$-behavior $[14,19]$. We assume $\beta_{1}=0$ for the highfrequency (or short timescale) component $W$, equivalent to an uncorrelated white noise time series and consistent with weather [12]. For the long-range climate component $C$ we simulate a power-law process with $\beta_{2} \in(0,1)$. The surrogate processes $T$ and $P$ are obtained as weighted means of $W$ and $C$ with weights $a$ and $b$ and $c$ as

$$
\begin{aligned}
& T=a W+b C+c N_{1} \\
& P=-a W+b C+c N_{2},
\end{aligned}
$$


where the sum of weights equals unity, $a+b+c=1$. $\beta_{1}$ is kept fixed, while the parameters $\beta_{2}=\beta, a, b$ and $c$ are varied in the fitting process to minimize the Root Mean Square Error (RMSE) between observed and simulated correlation between $T$ and $P . \quad N_{1}$ and $N_{2}$ represents independent observation noise on $T$ and $P$, and is simulated as Gaussian white noise. Pink noise processes were obtained by generating white noise signals, modifying their Fourier transform to obtain the desired slope and re-transforming them into the time domain. The co-variability between $T$ and $P$ was estimated after the removal of the millennial-timescale component, as for the paleoclimate proxy data.

Changing the parameters $\beta, a, b$ and $c$ effectively changes the relationships of the $T$ and $P$ time series. The stochastic model is timescale-dependent, if $\beta>0$. For example for $\beta=0$ the obtained time series represent temporally uncorrelated white noise, $\beta \in(0,1)$ thus allows for varying autocorrelation. Values of $\beta$ between 1 and 2 , on the other hand, would result in time series mimicking glacial-interglacial scale variations [2]. The ratio of $a$ and $b$ describes the relative importance of the long-range positive correlation between $T$ and $P$, whereas parameter $c$ describes independent observational noise.

\subsubsection{Comparison}

The parameters of the model were derived by minimizing the RMSE between the correlation estimates from the stochastic model and the climate model and observation-derived correlation estimates from interannual to centennial timescales (the dashed lines in Fig. 4). The best fit to the instrumental and proxy data is obtained for $\beta=0.5, a=0.5, b=0.4$ and $c=0.1$, which describes a smooth transition from a negative correla- 


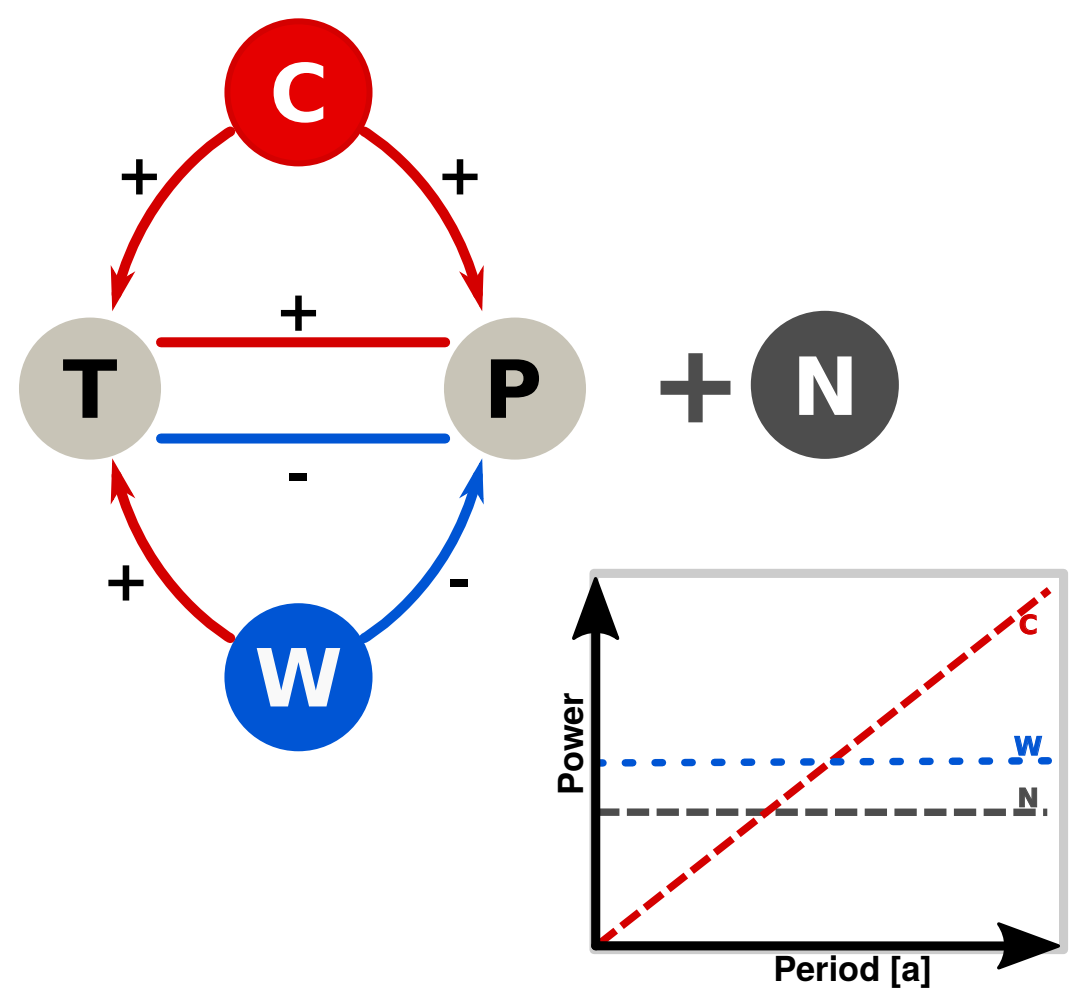

Figure 7: Illustration of the coupling scheme and spectral characteristics of generating processes in the stochastic model. The final processes $T$ and $P$ are obtained as a linear combination of $W, C$ and $N$. The influence from process $W$ results in a negative correlation between $T$ and $P$, that of $C$ in a positive correlation. On short timescales $W$ has a stronger weight, on long timescales $C$ dominates. Additional, mutually independent, observation noise $N$ is added to both $T$ and $P$. 
tion between temperature and precipitation on annual to decadal timescale, to a positive correlation on multidecadal/centennial scale. By contrast, to mimic the covariance simulated by the climate models, the stochastic model needs a weaker timescale dependence $(\beta=0.25)$, a smaller influence of $\mathrm{C}$ $(b=0.3)$ and a stronger noise component $(c=0.2)$. The lower $\beta$ of the historical/past1000/orbital model fit suggests lower climate variability on longer timescales than in the observations. At the same time, positive associations on long timescales are weaker, as $b$ has to be reduced.

The stochastic model results support a potential explanation for the discrepancy between models and observations: Weak long-term climate variability in the models, together with less intrinsic positive relationships between local temperature and precipitation, potentially due to soil moisture biases and poor rainfall simulation, yield overall negative associations.

\section{Conclusion}

We have shown that CMIP5/PMIP3 climate model simulations and paleoclimate proxy data suggest considerably different relationships between temperature and precipitation in Asia on long timescales: Model results suggest, that warmer centuries should have been dryer - proxy results suggest that they were wetter. While we cannot completely rule out systematic biases in the reconstructed T-P relationship, considering the known proxy uncertainties such as seasonal attribution of the proxy recording system or noise on the proxy records did not resolve the model-data mismatch. Further, independent results such as spatially consistent dry/cold and wet/warm conditions in monsoonal Asia based on quantitative and semi-quantitative moisture in- 
dicators through the past millennium [7] support our proxy based results.

The observed timescale-dependent nature of the T-P relationship may explain the apparent lack of clear precipitation trends in the past 50 years of the instrumental record [44]: The shortness of the instrumental record only allows to derive synoptic to multidecadal relationships. According to our stochastic model bridging the instrumental and proxy data, negative T-P associations dominate at up to decadal timescales and a significant positive relationship should emerge on considerably longer timescales than 30-50 years. Thus, paleoclimate proxy data may reveal different aspects of the climate system than those emerging from the analyses of the short, high-resolution observational record only.

The positive relationship between temperature and precipitation on long timescales in the past may not be directly translated to a warmer and wetter future for Asia as the monsoon response to natural forcing and internal variability in the past may have been different to the response to future increased greenhouse gas emissions [e.g. 23]. However, our results call for a reconciliation of model-data mismatch in the precipitation-temperature relationship which needs attention from both the data and the modeling side.

On the climate model side, the mismatch may be due to intrinsic model aspects, the underestimation of the magnitude of natural forcing, or inadequate sensitivity to forcing [18]. Model sensitivity experiments where parameterizations, forcings or the coupling between components are varied [as e.g. 3, 4, 23] are helpful in this respect, in particular if experiments have been conducted for ensembles, or several models. On centennial timescales, the dynamic adjustment of currently fixed boundary conditions (such as ice 
sheets and mountain glaciers) may lead to stronger regional variability and may resolve part of the model-data mismatch we currently observe.

On the proxy side, the uncertainties of reconstructions have to be further explored. To this end, there has been increasing focus on the reconstructability of single or multiple climate variables, in particular from multivariate paleoecological data $[17,41]$. Also, spectral biases in proxy archives [as shown for tree-ring data in 10] warrant systematic investigation. Finally, with improved understanding of the processes influencing paleoclimate archives, proxy system models [8] might be developed, which may allow a better comparison of proxy and model (co)variability, and ultimately a resolution of the proxy-data mismatch in the T-P relationship.

\section{Acknowledgements}

We thank J. Jungclaus and N. Fischer for providing the orbital simulation; as well as Martina Stebich, Sebastian F.M. Breitenbach, Sze Ling Ho and Richard Telford for discussion. We also thank Michel Crucifix and an anonymous reviewer for their constructive comments. We acknowledge the World Climate Research Programme's Working Group on Coupled Modeling, which is responsible for CMIP, and thank the climate modeling groups for producing and making available their model output. The US Department of Energy's Programme for Climate Model Diagnosis and Intercomparison provided coordinating support for CMIP5 and led development of software infrastructure in partnership with the Global Organization for Earth System Science Portals. The PMIP3 Data archives are supported by CEA and CNRS. The CRU Hulme precipitation dataset 'gu23wld0098.dat' (Version 
1.0) was constructed by Dr Mike Hulme at the Climatic Research Unit, University of East Anglia, Norwich, UK. The construction of this dataset has been supported by the UK Department of the Environment, Transport and the Regions (Contract EPG 1/1/85). All data sources are given in Supplementary Table 3. This study was supported by the Initiative and Networking Fund of the Helmholtz Association grant no. VG-900NH.

\section{References}

[1] Adler, R. F., Gu, G., Wang, J.-J., Huffman, G. J., Curtis, S., Bolvin, D., nov 2008. Relationships between global precipitation and surface temperature on interannual and longer timescales (1979-2006). J. Geophys. Res. 113 (D22), D22104.

[2] Ashkenazy, Y., Baker, D. R., Gildor, H., Havlin, S., 2002. Nonlinearity and Multifractality of Climate Change in the Past 420,000 Years 30 (22), $3-6$.

[3] Berg, A., Lintner, B. R., Findell, K., Seneviratne, S. I., van den Hurk, B., Ducharne, A., Chéruy, F., Hagemann, S., Lawrence, D. M., Malyshev, S., Meier, A., Gentine, P., 2015. Interannual Coupling between Summertime Surface Temperature and Precipitation over Land: Processes and Implications for Climate Change. J. Clim. 28 (3), 1308-1328.

[4] Bush, S. J., Turner, A. G., Woolnough, S. J., Martin, G. M., Klingaman, N. P., 2014. The effect of increased convective entrainment on Asian monsoon biases in the MetUM general circulation model. 
[5] Caley, T., Roche, D. M., Renssen, H., 2014. Orbital Asian summer monsoon dynamics revealed using an isotope-enabled global climate model. Nat. Commun. 5, 5371.

[6] Chao, W. C., 2012. Correction of Excessive Precipitation over Steep and High Mountains in a GCM.

[7] Chen, J., Chen, F., Feng, S., Huang, W., Liu, J., Zhou, A., 2015. Hydroclimatic changes in China and surroundings during the Medieval Climate Anomaly and Little Ice Age: spatial patterns and possible mechanisms. Quat. Sci. Rev. 107, 98-111.

[8] Evans, M., Tolwinski-Ward, S., Thompson, D., Anchukaitis, K., 2013. Applications of proxy system modeling in high resolution paleoclimatology. Quat. Sci. Rev. 76, 16-28.6

[9] Fischer, N., Jungclaus, J. H., 2011. Evolution of the seasonal temperature cycle in a transient Holocene simulation: orbital forcing and sea-ice. Clim. Past 7 (4), 1139-1148.

[10] Franke, J., Frank, D., Raible, C. C., Esper, J., Brönnimann, S., 2013. Spectral biases in tree-ring climate proxies. Nat. Clim. Chang. 3 (4), $360-364$.

[11] Ge, Q., Hao, Z., Zheng, J., Shao, X., 2013. Temperature changes over the past 2000 yr in China and comparison with the Northern Hemisphere. Clim. Past 9 (3), 1153-1160.

[12] Hasselmann, K., 1976. Stochastic climate models Part I. Theory. Tellus 28 (6), 473-485. 
[13] Hulme, M., Osborn, T. J., Johns, T. C., 1998. Precipitation sensitivity to global warming: Comparison of observations with HadCM2 simulations. Geophys. Res. Lett. 25, 3379.

[14] Huybers, P., Curry, W., 2006. Links between annual, Milankovitch and continuum temperature variability. Nature 441 (7091), 329-32.

[15] IPCC, 2013. Climate Change 2013: The Physical Science Basis. Contribution of Working Group I to the Fifth Assessment Report of the Intergovernmental Panel on Climate Change. Cambridge University Press, Cambridge, United Kingdom and New York, NY, USA.

[16] Jones, P. D., Lister, D. H., Osborn, T. J., Harpham, C., Salmon, M., Morice, C. P., 2012. Hemispheric and large-scale land-surface air temperature variations: An extensive revision and an update to 2010. J. Geophys. Res. 117 (D5), D05127.

[17] Juggins, S., 2013. Quantitative reconstructions in palaeolimnology: new paradigm or sick science? Quat. Sci. Rev. 64, 20-32.

[18] Laepple, T., Huybers, P., 2014. Global and regional variability in marine surface temperatures. Geophys. Res. Lett. 41 (7), 2528-2534.

[19] Laepple, T., Huybers, P., 2014. Ocean surface temperature variability: Large model-data differences at decadal and longer periods. Proc. Natl. Acad. Sci. U. S. A.

[20] Leipe, C., Kito, N., Sakaguchi, Y., Tarasov, P. E., 2013. Vegetation and climate history of northern Japan inferred from the 5500-year pollen 
record from the Oshima Peninsula, SW Hokkaido. Quat. Int. 290-291, 151-163.

[21] Levermann, A., Schewe, J., Petoukhov, V., Held, H., 2009. Basic mechanism for abrupt monsoon transitions. Proc. Natl. Acad. Sci. U. S. A. 106 (49), 20572-7.

[22] Levine, R. C., Turner, A. G., Marathayil, D., Martin, G. M., 2013. The role of northern Arabian Sea surface temperature biases in CMIP5 model simulations and future projections of Indian summer monsoon rainfall. Clim. Dyn. 41 (1), 155-172.

[23] Liu, J., Wang, B., Ding, Q., Kuang, X., Soon, W., Zorita, E., 2009. Centennial variations of the global monsoon precipitation in the last millennium: Results from ECHO-G model. J. Clim. 22 (9), 2356-2371.

[24] Liu, Z., Zhu, J., Rosenthal, Y., Zhang, X., Otto-Bliesner, B. L., Timmermann, A., Smith, R. S., Lohmann, G., Zheng, W., Elison Timm, O., 2014. The Holocene temperature conundrum. Proc. Natl. Acad. Sci., $1-5$.

[25] Lovejoy, S., Schertzer, D., Varon, D., 2013. Do GCMs predict the climate ... or macroweather? Earth Syst. Dyn. 4 (2), 439-454.

[26] Lu, H., Wu, N., Liu, K., Jiang, H., Liu, T., 2007. Phytoliths as quantitative indicators for the reconstruction of past environmental conditions in China II: palaeoenvironmental reconstruction in the Loess Plateau. Quat. Sci. Rev. 26 (5-6), 759-772. 
[27] Meehl, G. A., Covey, C., Delworth, T., Latif, M., McAvaney, B., Mitchell, J. F. B., Stouffer, R. J., Taylor, K. E., 2007. The WCRP CMIP3 multimodel dataset: A new era in climatic change research. Bull. Am. Meteorol. Soc. 88 (September), 1383-1394.

[28] Menon, A., Levermann, A., Schewe, J., Lehmann, J., Frieler, K., 2013. Consistent increase in Indian monsoon rainfall and its variability across CMIP-5 models. Earth Syst. Dyn. 4 (2), 287-300.

[29] Mueller, B., Seneviratne, S. I., 2014. Systematic land climate and evapotranspiration biases in CMIP5 simulations. Geophys. Res. Lett. 41 (1), $128-134$.

[30] Pages2k-Consortium, 2013. Continental-scale temperature variability during the past two millennia. Nat. Geosci. 6 (5), 339-346.

[31] Peterson, T., Vose, R., 1997. An overview of the Global Historical Climatology Network temperature database. Bull. Am. Meteorol. Soc. 78 (12), $2837-2849$.

[32] Rehfeld, K., Kurths, J., 2014. Similarity estimators for irregular and age-uncertain time series. Clim. Past 10 (1), 107-122.

[33] Rehfeld, K., Marwan, N., Breitenbach, S. F. M., Kurths, J., 2013. Late Holocene Asian Summer Monsoon dynamics from small but complex networks of palaeoclimate data. Clim. Dyn. 41 (1), 3-19.

[34] Schneider, T., Bischoff, T., Haug, G. H., 2014. Migrations and dynamics of the intertropical convergence zone. Nature 513 (7516), 45-53. 
[35] Sheppard, P. R., Tarasov, P. E., Graumlich, L. J., Heussner, K.-U., Wagner, M., Sterle, H., Thompson, L. G., 2004. Annual precipitation since 515 BC reconstructed from living and fossil juniper growth of northeastern Qinghai Province, China. Clim. Dyn. 23 (7-8), 869-881.

[36] Sperber, K. R., Annamalai, H., Kang, I.-S., Kitoh, A., Moise, A., Turner, A., Wang, B., Zhou, T., 2012. The Asian summer monsoon: an intercomparison of CMIP5 vs. CMIP3 simulations of the late 20th century. Clim. Dyn. 41 (9-10), 2711-2744.

[37] Stebich, M., Rehfeld, K., Schlütz, F., Tarasov, P. E., Liu, J., Mingram, J., 2015. Holocene vegetation and climate dynamics of NE China based on the pollen record from Sihailongwan Maar Lake. Quat. Sci. Rev. 124, $275-289$.

[38] Tan, L., Cai, Y., An, Z., Yi, L., Zhang, H., Qin, S., 2011. Climate patterns in north central China during the last $1800 \mathrm{yr}$ and their possible driving force. Clim. Past 7 (3), 685-692.

[39] Tan, M., Liu, T., Hou, J., Quin, X., Zhang, H., Li, T., 2003. Cyclic rapid warming on centennial-scale revealed by a 2650-year stalagmite record of warm season temperature. Geophys. Res. Lett. 30 (12).

[40] Taylor, K. E., Stouffer, R. J., Meehl, G. A., 2012. An Overview of CMIP5 and the Experiment Design. Bull. Am. Meteorol. Soc. 93 (4), 485-498.

[41] Telford, R. J., Birks, H. J. B., 2011. A novel method for assessing the statistical significance of quantitative reconstructions inferred from biotic assemblages. Quat. Sci. Rev. 30 (9-10), 1272-1278. 
[42] Trenberth, K. E., 2005. Relationships between precipitation and surface temperature. Geophys. Res. Lett. 32 (14), 2-5.

[43] Treydte, K. S., Schleser, G. H., Helle, G., Frank, D. C., Winiger, M., Haug, G. H., Esper, J., 2006. The twentieth century was the wettest period in northern Pakistan over the past millennium. Nature 440 (7088), 1179-82.

[44] Turner, A. G., Annamalai, H., 2012. Climate change and the South Asian summer monsoon. Nat. Clim. Chang. 2 (8), 587-595.

[45] Wang, G., Kim, Y., Wang, D., 2007. Quantifying the Strength of Soil Moisture-Precipitation Coupling and Its Sensitivity to Changes in Surface Water Budget. J. Hydrometeorol. 8 (3), 551-570.

[46] Williams, C. J. R., Allan, R. P., Kniveton, D. R., 2012. Diagnosing atmosphere-land feedbacks in CMIP5 climate models. Environ. Res. Lett. 7 (4), 044003.

[47] Xu, Q., Xiao, J., Li, Y., Tian, F., Nakagawa, T., 2010. Pollen-Based Quantitative Reconstruction of Holocene Climate Changes in the Daihai Lake Area, Inner Mongolia, China. J. Clim. 23 (11), 2856-2868.

[48] Yi, L., Yu, H., Ge, J., Lai, Z., Xu, X., Qin, L., Peng, S., 2011. Reconstructions of annual summer precipitation and temperature in northcentral China since 1470AD based on drought/flood index and tree-ring records. Clim. Change 110 (1-2), 469-498.

[49] Zhang, P., Cheng, H., Edwards, R. L., Chen, F., Wang, Y., Yang, X., Liu, J., Tan, M., Wang, X., Liu, J., An, C., Dai, Z., Zhou, J., Zhang, 
661

D., Jia, J., Jin, L., Johnson, K. R., 2008. A Test of Climate, Sun, and Culture Relationships from an 1810-Year Chinese Cave Record. Science. 322 (5903), 940-942.

[50] Zhang, Y., Li, T., Wang, B., 2004. Decadal change of the spring snow depth over the Tibetan Plateau: The associated circulation and influence on the East Asian summer monsoon. J. Clim. 17, 2780-2793. 


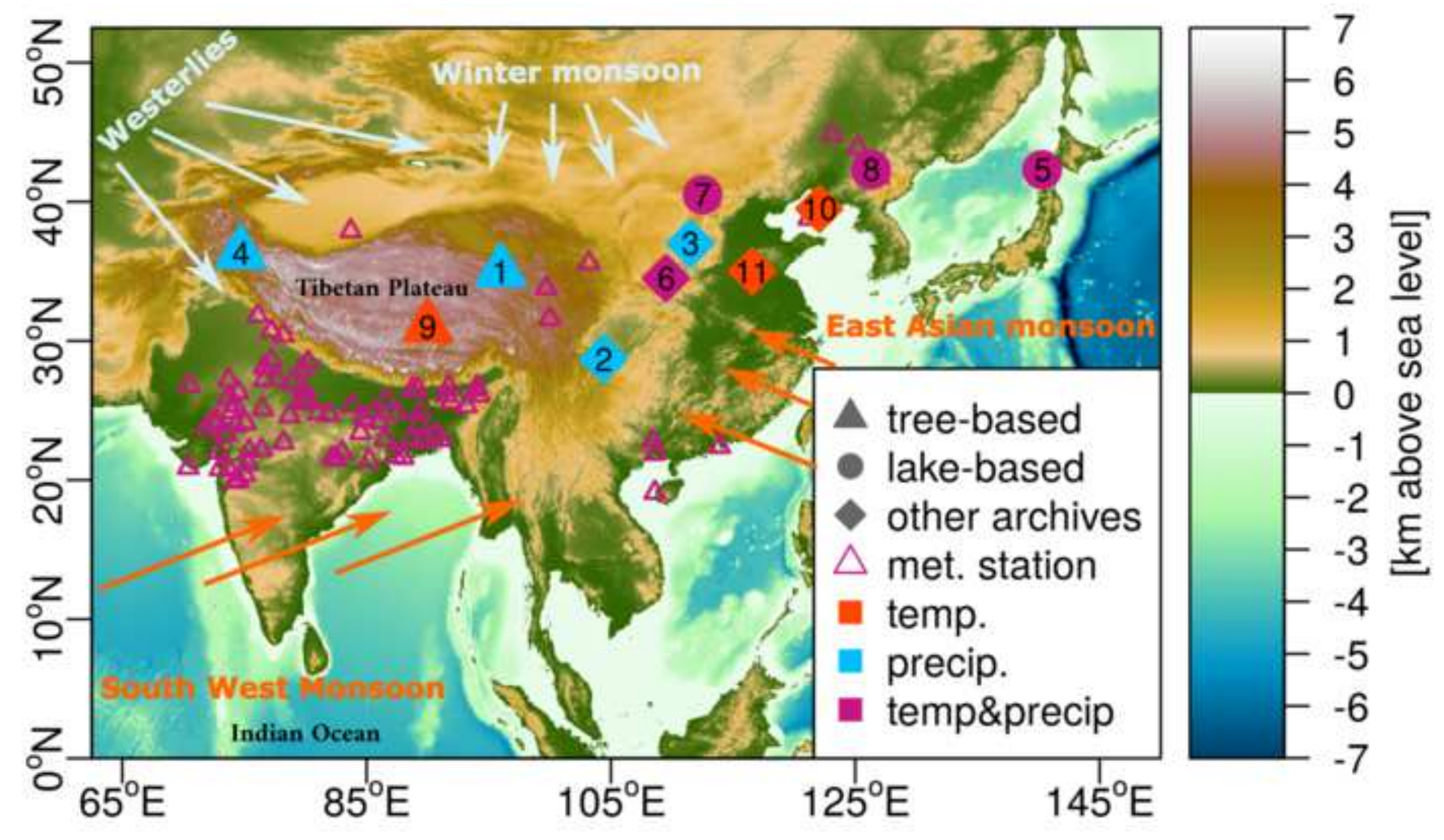


Figure (a) Reconstruction-based correlations

(3:11) NC:Ge(3:10) NC:Shihua(8:8) SHL:SHL(7:7) Daihai:Daihai(6:6) Loess:Loess (5:5) YAK:YAK (1:9) Shep:Pages2K(4:9) Kara:Pages2K(2:9) Tan:Pages2K(2:10) Tan:Shihua(2:11) Tan:Ge

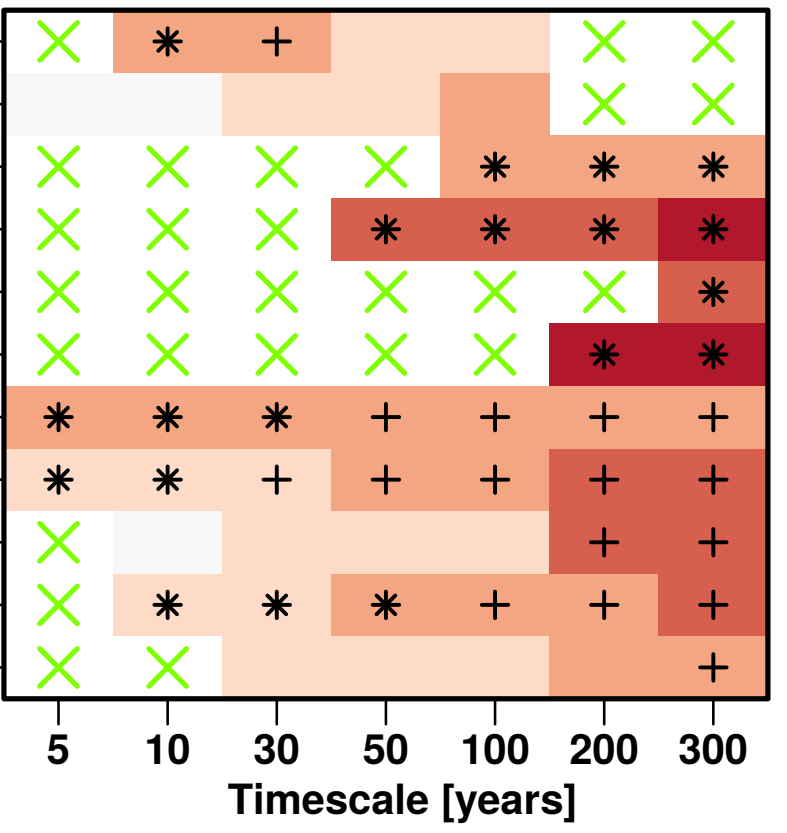

(b) Model-based correlations (30 yr. timescale)

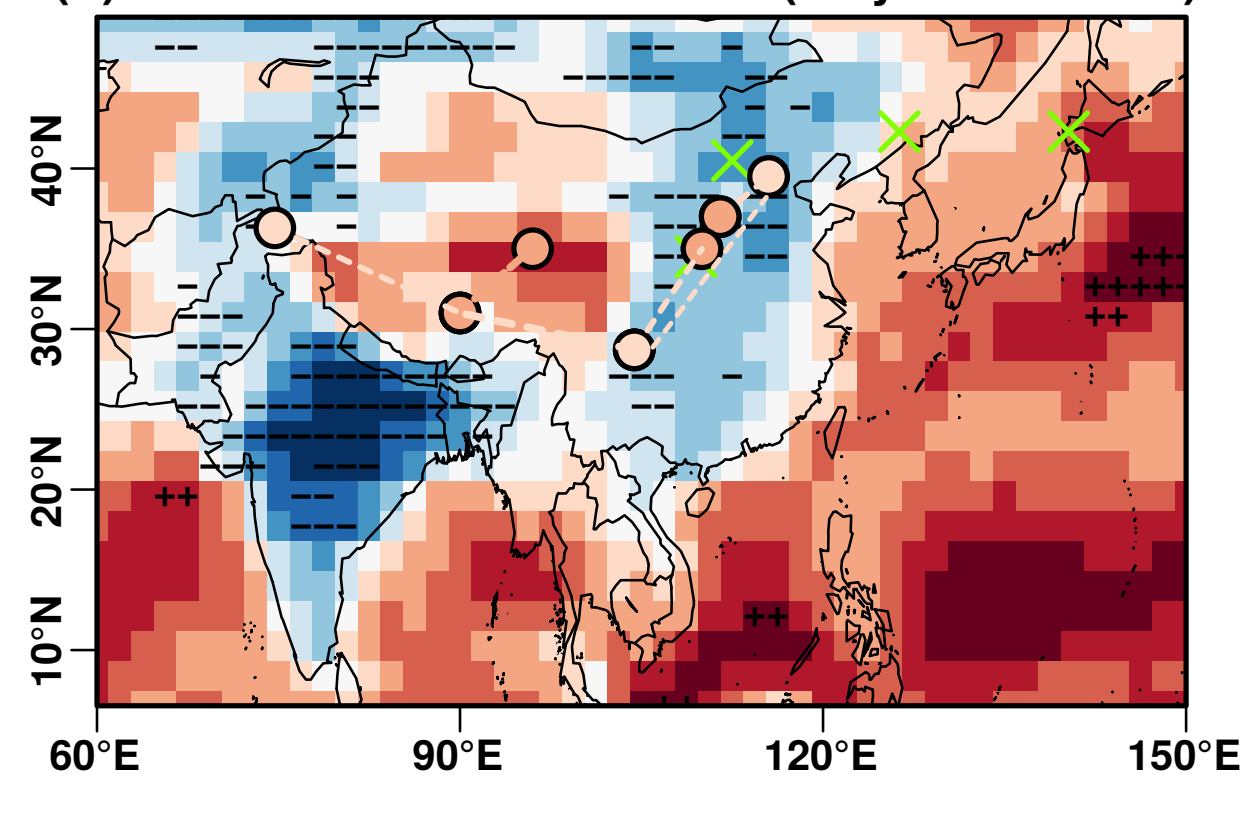


Figure 4

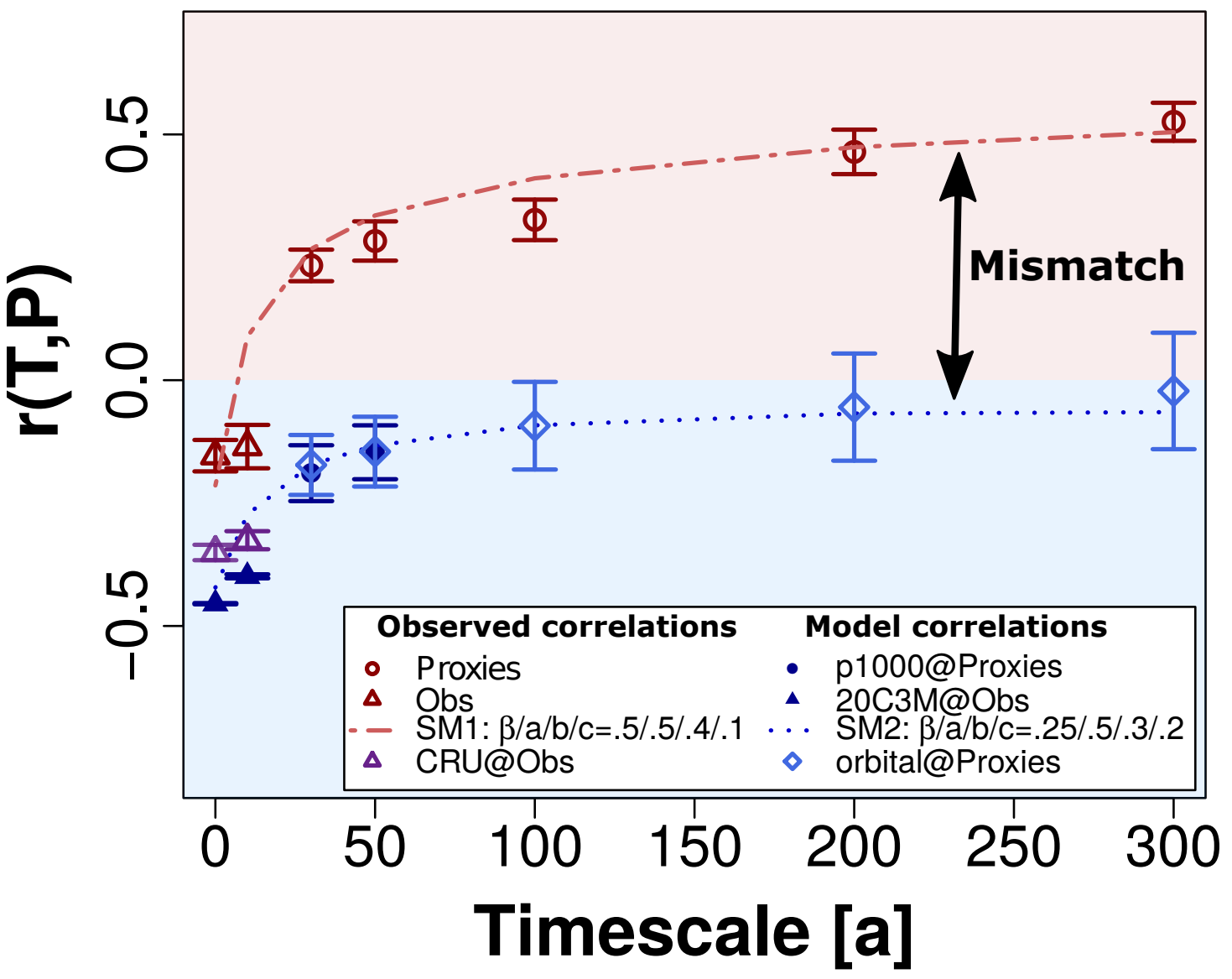


Figues 5

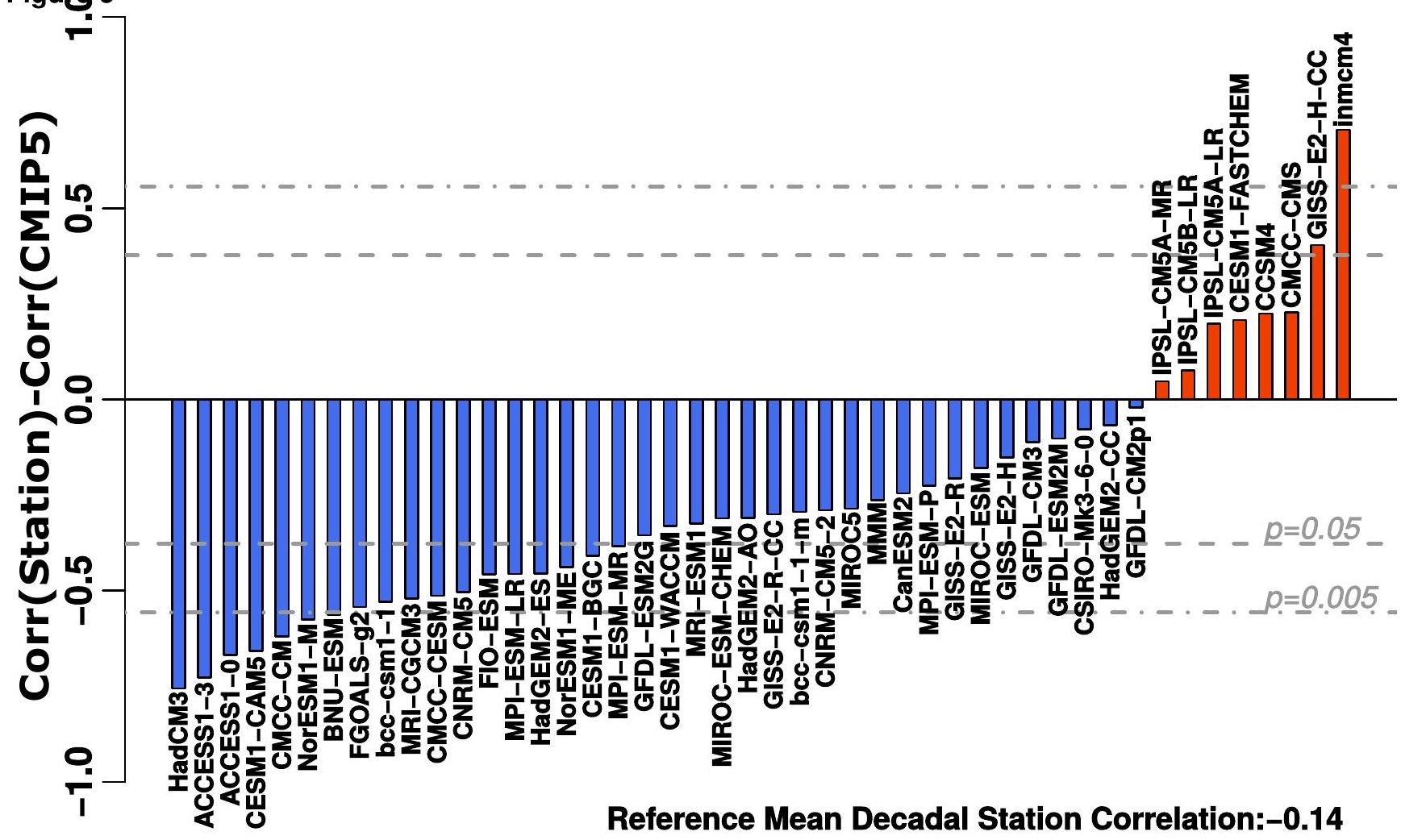


Figure 6 a: temperature/precipitation

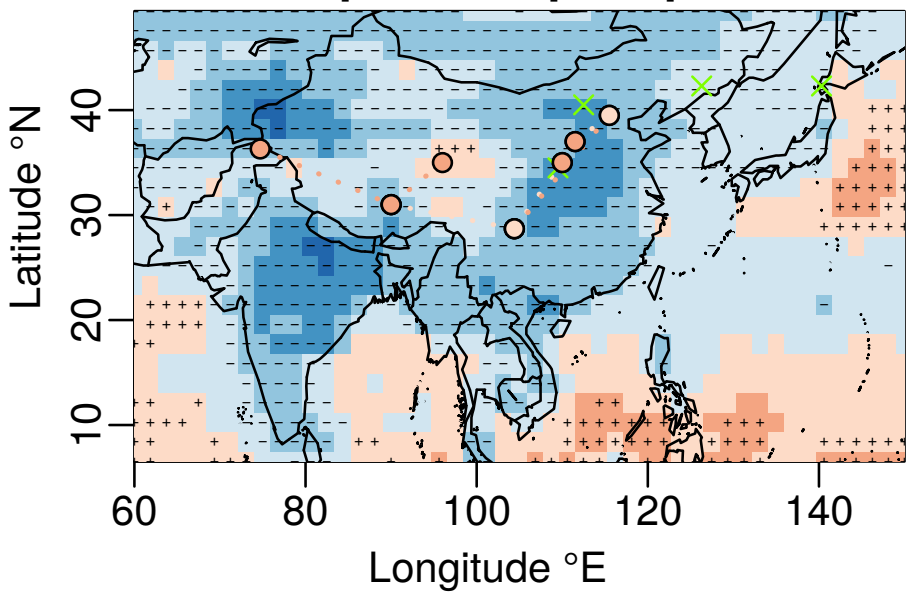

b: temperature/soil moisture

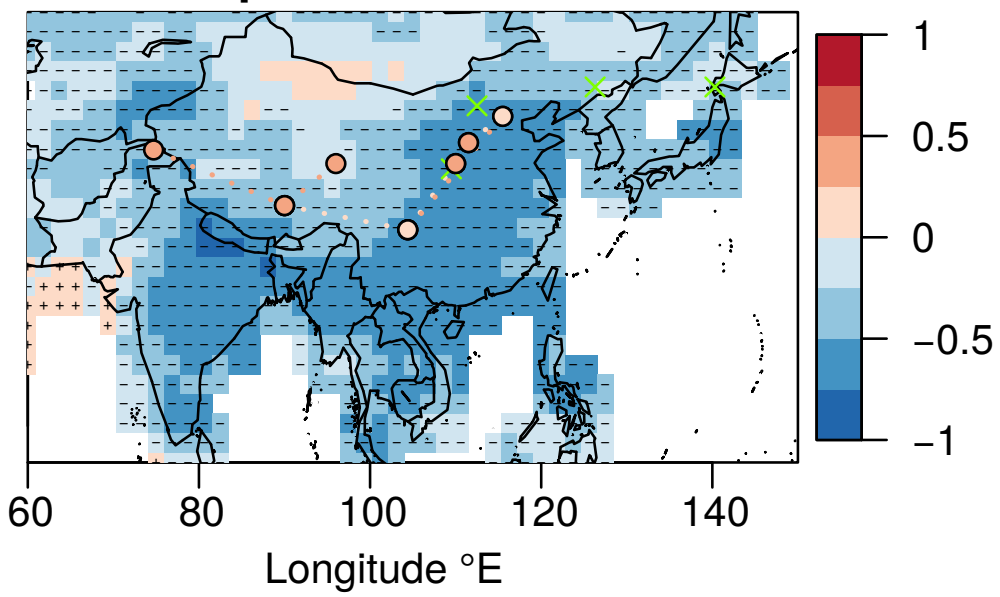




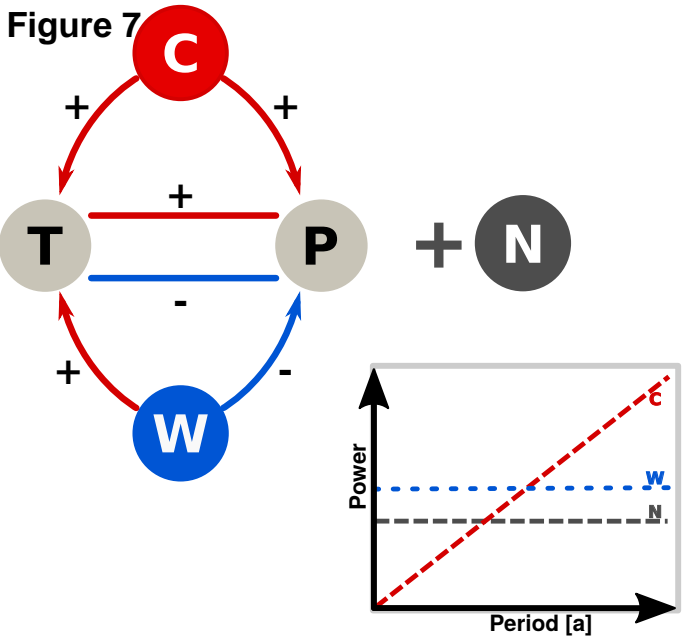

